BMJ Open

Diabetes

Research

\& Care

\title{
Coxsackie-adenovirus receptor expression is enhanced in pancreas from patients with type 1 diabetes
}

\author{
M Hodik, ${ }^{1}$ M Anagandula, ${ }^{1} \mathrm{~J}$ Fuxe,${ }^{2}$ L Krogvold, ${ }^{3} \mathrm{~K}$ Dahl-Jørgensen, ${ }^{3} \mathrm{H}$ Hyöty,,${ }^{4,5}$ \\ L Sarmiento, ${ }^{6}$ G Frisk, ${ }^{1}$ POD-V Consortium
}

To cite: Hodik M, Anagandula M, Fuxe J, et al. Coxsackie-adenovirus receptor expression is enhanced in pancreas from patients with type 1 diabetes. BMJ Open Diabetes Research and Care 2016;4:e000219. doi:10.1136/bmjdrc-2016000219

- Additional material is available. To view please visit the journal (http://dx.doi.org/ 10.1136/bmjdrc-2016000219)

Received 29 February 2016 Revised 8 June 2016 Accepted 9 July 2016

CrossMark

For numbered affiliations see end of article.

Correspondence to Dr Gun Frisk; gun.ergida. frisk@gmail.com

\section{ABSTRACT}

Objectives: One of the theories connecting enterovirus (EV) infection of human islets with type 1 diabetes (T1D) is the development of a fertile field in the islets. This implies induction of appropriate proteins for the viral replication such as the coxsackieadenovirus receptor (CAR). The aim of this study was to investigate to what extent CAR is expressed in human islets of Langerhans, and what conditions that would change the expression.

Design: Immunohistochemistry for CAR was performed on paraffin-embedded pancreatic tissue from patients with T1D ( $n=9$ recent onset T1D, $n=4$ long-standing T1D), islet autoantibody-positive individuals $(n=14)$ and non-diabetic controls $(n=24)$ individuals. The expression of CAR was also examined by reverse transcription PCR on microdissected islets $(n=5)$, exocrine tissue $(n=5)$ and on explanted islets infected with EV or exposed to chemokines produced by EV-infected islet cells.

Results: An increased frequency of patients with T1D and autoantibody-positive individuals expressed CAR in the pancreas $(p<0.039)$. CAR staining was detected more frequently in pancreatic islets from patients with $\mathrm{T} 1 \mathrm{D}$ and autoantibody-positive subjects (15/27) compared with $(6 / 24)$ non-diabetic controls $(p<0.033)$. Also in explanted islets cultured in UV-treated culture medium from coxsackievirus B (CBV)-1-infected islets, the expression of the CAR gene was increased compared with controls. Laser microdissection of pancreatic tissue revealed that CAR expression was 10-fold higher in endocrine compared with exocrine cells of the pancreas. CAR was also expressed in explanted islets and the expression level decreased with time in culture. CBV-1 infection of explanted islets clearly decreased the expression of CAR $(p<0.05)$. In contrast, infection with echovirus 6 did not affect the expression of CAR.

Conclusions: CAR is expressed in pancreatic islets of patients with T1D and the expression level of CAR is increased in explanted islets exposed to proinflammatory cytokines/chemokines produced by infected islets. T1D is associated with increased levels of certain chemokines/cytokines in the islets and this might be the mechanism behind the increased expression of CAR in TID islets.

\section{INTRODUCTION}

Type 1 diabetes (T1D) is a lifelong disease characterized by the loss of or severely

\section{Significance of this study}

What is already known about this subject?

- It is known that enterovirus, especially Coxsackievirus B, often can be detected in human islets of Langerhans in type 1 diabetes cases.

\section{What are the new findings?}

- It is not known if and to what extent islet cells express appropriate virus receptors and if the expression differs between type 1 diabetes cases, pre-diabetic cases and non-diabetes individuals.

How might these results change the focus of research or clinical practice?

- Our finding that the Coxsackie-AdenvirusReceptor (CAR) is more frequently expressed in pancreas from pre-diabetic and in type 1 diabetes cases compared to control individuals suggest the presence of a fertile field in pancreas in the two former groups.

reduced number of insulin-producing $\beta$ cells in the islet of Langerhans, presence of islet autoantibodies and, especially in younger individuals, insulitis consisting of infiltration of the islets predominantly by CD8+ T cells and macrophages. The etiology of the disease is unclear but it has been shown that genetic factors, especially genes in the human leucocyte antigen (HLA) complex, are of major importance for the pathogenesis. In addition, several studies have shown that environmental factors likely contribute to disease development. $^{1}{ }^{2}$ Enteroviruses (EVs), particularly the coxsackievirus B (CBV), are among the main environmental candidates and numerous studies have shown association between these gut viruses and T1D by different techniques. $^{3-10}$ In addition, experiments using isolated human islets have shown that CBVs are able to infect and replicate in insulinproducing $\beta$ cells. ${ }^{4}$ 11-13

CBV belong to the human enterovirus species B (HEV-B) species. Their genome is 
$\sim 7500$ nucleotides long and protected by a capsid composed of 180 subunits of the capsid proteins VP1-VP4.

The virions use various receptor molecules to enter the cell. The main receptor for CBVs is the tight junction protein Coxsackie-adenovirus receptor (CAR), which belongs to the large family of adhesion molecules; however, other receptors have also been shown to be important for virus internalization. ${ }^{14}{ }^{15}$ The full-length CAR protein comprises two extracellular immunoglobulin-like domains (D1 and D2), one transmembrane helix and an intracellular C-terminal domain. ${ }^{16}{ }^{17}$ At least five isoforms of CAR are known, two transmembrane isoforms, which differ only at their C-terminal, and three lacking the transmembrane domain that were shown to be secreted in transfected HeLa cells. ${ }^{18-20}$ CBV binds the distal end of the D1 domain in the canyon of the virus capsid, ${ }^{21}$ whereas the intracellular $\mathrm{C}$ domain has been shown to be dispensable for infection. ${ }^{22}$ The tissue distribution of CAR in human tissues has been mainly studied at the transcriptional level; CAR is expressed in a variety of human organs, including the pancreas. ${ }^{19} 23$ The protein is highly expressed in the brain and heart during murine embryonic development, but expression declines rapidly after birth. $^{24}{ }^{25}$ Expression of the CAR protein in human adult pancreas has been demonstrated in ductal epithelial cells, ${ }^{26}$ islet cells, ${ }^{27}$ and exocrine acinar cells (http:// www.proteinatlas.org) by immunohistochemistry (IHC). Which of the isoforms of the CAR protein is present in pancreas, and the biological functions of these are not known. A monoclonal antibody directed against the extracellular CAR domain ${ }^{28}$ blocked replication of CBV-4 and CBV-5 in explanted islets, an indirect proof of expression and function in human islets. ${ }^{4}$ Furthermore, the expression of the CAR protein has been noted to be increased during healing and inflammation ${ }^{29} 30$ and downregulated in various human cancers. ${ }^{31}$

The main aim of this study was to investigate the expression of the CAR gene and protein in pancreatic tissue, obtained from different groups of patients with T1D, and to compare it with non-diabetic control individuals. We also wanted to study how EV infection or virus-induced inflammatory mediators regulate the expression of CAR in human islets.

\section{MIATERIALS AND METHODS}

\section{Tissue specimen}

Pancreatic paraffin-embedded tissue from the pancreatic head or tail were obtained from non-diabetic donors with islet cell autoantibodies $(\mathrm{n}=14)$, donors with recent onset T1D $(n=9$, both from organ donors and from the DiViD study), donors with long-standing T1D ( $n=5)$, and from control, autoantibody-negative, non-diabetic organ donors $(n=24)$. Tissues from organ donors were provided by the Network for Pancreatic Organ Donors with Diabetes (nPOD) and the Uppsala biobank. Pancreas biopsies were obtained from the DiViD biobank, Oslo, Norway (see online supplementary table S1).

\section{Human islet and cell cultures}

Pancreatic islets were isolated from the pancreas of organ donors according to the protocol by Goto et al. ${ }^{32}$ Islets were then handpicked under a light microscope to further increase purity to $>90 \%$. Islets were cultured free floating in six-well plates for suspension cultures (Sarstedt, Nümbrecht, Germany) in $3 \mathrm{~mL}$ RPMI-1640 $5.5 \mathrm{mM}$ glucose (SVA, Uppsala Sweden) supplemented with $10 \%$ fetal bovine serum (FBS) (Gibco, Invitrogen, Stockholm, Sweden). Green Monkey Kidney (GMK) cells were cultured in 96-well plates (Corning, New York, USA) in Eagle's minimum essential medium (EMEM) (SVA, Uppsala Sweden) supplemented with 10\% FBS (Gibco, Invitrogen, Stockholm, Sweden). All cells were cultured at $37^{\circ} \mathrm{C}$ in $5 \% \mathrm{CO}_{2}$.

\section{Prolonged culture of islets}

Human islets, isolated and further purified by handpicking, were cultured as described above with change of culture medium every third day. Total RNA was extracted on days $1,4,8$ and 13 (number of donors=2) postisolation to analyze the genes coding for CAR and insulin.

\section{Ethics}

The work performed on human tissue was in accordance with the principles expressed in the Declaration of Helsinki and the European Council's Convention on Human Rights and Biomedicine. Isolation of human islets of Langerhans and the research performed on these was approved by the Regional Ethics Committee in Uppsala, Sweden. Collection of pancreatic tissue in the DiViD study was approved by the Norwegian Government Regional Ethics Committee in Oslo, Norway.

\section{Virus}

Three strains of CBV-1 were used in the gene expression study: CBV-1-7-10796 and CBV-1-11-10802 were isolated in Argentina during 1983 and 1998, respectively, whereas CBV-1-3-10790 was isolated in the USA in 1973. All strains were obtained from the Center for Disease Control and Prevention (CDC), Atlanta, Georgia, USA. In addition, a strain of echovirus 6 (Echo-6-2C) was included in this study. This strain was isolated in Cuba 2011 from a patient with meningitis as a part of the Public Health Surveillance strategies in Cuba on circulating $\mathrm{EV}$ in meningitis cases. The CBV-1 strains were chosen since CBV-1 has been shown to use CAR as its main receptor. The Echo-6-2C strain was chosen since this serotype does not use CAR as a receptor and has been shown to bind to CD55/decay accelerating factor. ${ }^{33}$

\section{Immunohistochemistry}

Paraffin-embedded formalin-fixed pancreatic tissue as well as paraffin-embedded formalin-fixed explanted islets of Langerhans were sectioned $(5 \mu \mathrm{m})$ and dried on Superfrost glass slides (Menzel-Gläzer, Fischer scientific, Braunschweig, Germany), followed by de-paraffinization and rehydration in $99.70 \%$ ethanol. Antigen retrieval 
was performed in TE-buffer, pH 9 (DAKO, Glostrup, Denmark) in a steam boiler and permeabilized in TBS containing $0.05 \%$ TWEEN 20. Endogenous peroxidase was blocked by the use of a ready-to use peroxidase blocker (DAKO, Glostrup, Denmark). After rinsing, the sections were incubated with primary antibodies, mouse anti-CAR (RmcB clone, Millipore, Billerica, Massachusetts, USA) diluted 1:1000. Incubation with these antibodies was performed at room temperature for 1 hour and the visualization was achieved with the antimouse Envision-kit (Dako, Glostrup, Denmark) using 3,3'-diaminobenzidine (DAB) as substrate chromogen. For double staining with CAR and chromogranin A (mouse, ready to use, Dako, Glostrup), the sections were visualized using a Polink DS MM D kit polymer-HRP\&AP double staining kit (Golden Bridge, Mukilteo, Washington, USA).

\section{Virus infection}

Handpicked human islets of Langerhans were inoculated with any of the virus strains to obtain a final concentration of $10^{3}$ tissue culture infectious dose (TCID) $)_{50}$. Aliquots of the culture medium were collected on the day of infection and every day until day 3 postinfection (p.i.) for virus replication measurement by TCID $_{50}$ titrations, and stored at $-20^{\circ} \mathrm{C}$. On day 3 p.i., all islets and all cells detached from the islets during culture were spun down and washed before total RNA was extracted. Islets inoculated with the CBV-1-11 strain were also harvested for western blot (WB) analysis on day 3 p.i. For IHC analysis, islets from the same donor were inoculated with CBV-1-11 at a final concentration of $10^{2.5-3}$ TCID $_{50}$ or mock-infected. On day 4 p.i., they were fixed and embedded.

\section{Analysis of virus replication}

Virus replication was determined by TCID $_{50}$ titrations of samples of culture medium on an in house cell line originating from GMK cells, obtained from Gothenburg University, Sweden, as described previously. ${ }^{34}$ The samples were collected from the infected islet cultures on the indicated days p.i.

\section{Treatment with virus-induced proinflammatory chemokines}

The effect of inflammatory mediators on the expression level of the CAR gene was analyzed by treating explanted islets with UV-treated culture medium from CBV-1-infected human islets (two donors) and by adding CXCL10 (Peprotech, Stockholm, Sweden) at final concentrations of $0.1,10$ and $50 \mathrm{ng} / \mathrm{mL}$ (four donors) for 1 and 4 days. Total RNA was extracted and the expression of the gene encoding CAR was analyzed by quantitative reverse transcription PCR.

\section{RNA extraction and cDNA synthesis}

Three days p.i., isolated human pancreatic islets were washed in phosphate-buffered saline (PBS) and lysed by using RLT buffer (Qiagen, Sollentuna, Sweden) on
QIAshredder spin columns (Qiagen, Sollentuna, Sweden). Total RNA was extracted from the infected and control islets by using the RNAeasy mini kit (Qiagen, Sollentuna, Sweden) with G DNA eliminator column to remove the genomic DNA. RNA concentration and quality were determined with Nanodrop (Thermo Scientific, Braunschweig, Germany). Up to $50 \mathrm{ng}$ of total RNA per sample was reverse transcribed to cDNA in a reaction mixture of $0.5 \mu \mathrm{L}$ random primer (300 ng/ $\mu \mathrm{L}$, Invitrogen, Stockholm, Sweden), $1 \mu \mathrm{L}$ RNaseOUT $(40 \mathrm{U} / \mu \mathrm{L}), 4 \mu \mathrm{L} 5 \times$ first strand buffer, and $1 \mu \mathrm{L} 0.1 \mathrm{M}$ dithiothreitol (DTT) according to the manufacturer's instructions. Reaction was carried out at $25^{\circ} \mathrm{C}$ for $10 \mathrm{~min}, 42^{\circ} \mathrm{C}$ for $55 \mathrm{~min}$, and $15 \mathrm{~min}$ at $75^{\circ} \mathrm{C}$.

\section{Real-time PCR}

The mRNA expression level of genes encoding CAR, insulin, and amylase was analyzed with real-time PCR. The reaction mixture consisting of $10 \mu \mathrm{L}$ Syber Green master mix (Applied Biosystems, Stockholm, Sweden), $2 \mu \mathrm{L}$ primer, and $1 \mu \mathrm{L}$ cDNA was prepared according to the manufacturer's instructions. The reaction was carried out in a 96-well optical plate on a Step one plus Real-time PCR system (Applied Biosystems, Stockholm, Sweden). The cycling conditions were 40 cycles of $15 \mathrm{~s}$ at $94^{\circ} \mathrm{C}, 30 \mathrm{~s}$ at $55^{\circ} \mathrm{C}$ and $30 \mathrm{~s}$ at $68^{\circ} \mathrm{C}$. Predesigned primers (Quntitect, Qiagen, Sollentuna Sweden) were used for detection of CAR and 18s. Also, for amylase and insulin, commercially available primers were used for analyses of the LMC samples. Real-time PCR data were analyzed by the comparative delta ct method. The expression level of the gene encoding CAR was normalized to the expression of the 18 s housekeeping gene by subtracting the $18 \mathrm{~s} \mathrm{ct}$ value from CAR gene $\mathrm{ct}$ values. The relative gene expression levels were calculated by using the $2^{\wedge}{ }^{\text {dct }}$ formula and presented as the clustered columns in MS Excel. Melt curve analysis was used to verify the specificity of final PCR products.

\section{Western blot}

Expression of the CAR protein was analyzed in explanted human islets infected with CBV-1-11 and mock infected by WB using a polyclonal antibody $\left(\alpha\right.$-CAR20) as previously described, ${ }^{35}$ using an antibody against calnexin (BioNordika Sweden AB, Stockholm) as loading control.

\section{Statistical analyses}

Linear regression and ORs with 95\% CIs were used to test the likelihood of CAR positivity in grouped T1D donors and non-diabetic controls. Owing to low sample sizes, the likelihood of CAR positivity in the separate T1D groups was only measured between autoantibodypositive donors and non-diabetic controls. Differences in gene expression levels between control and virus-infected samples, between different donors and between the CBV-1 strains were analyzed with the Kruskal-Wallis test (corresponding to the parametric 
one-way analysis of variance), when comparing data from more than two independent groups, and the Mann-Whitney test (corresponding to the parametric independent samples t-test), when comparing data from two independent groups. Correlation analyses between the expression of amylase and exocrine tissue, insulin and endocrine tissue, and CAR and endocrine/exocrine tissue were performed with Spearman's $r$. The $p<0.05$ was considered statistically significant. All bars are presented as mean+SEM.

\section{RESULTS}

\section{Immunohistochemistry}

CAR positivity was significantly higher in the combined T1D and islet autoantibody-positive group (15/27 compared with controls $(6 / 24)$ in linear regression $(\mathrm{p}<0.033)$, with an OR of 3.877 and between islet autoantibody-positive subjects and non-diabetic controls $(p<0.039))$. The exact figure of this higher frequency of CAR-positive staining in the endocrine islets of recent onset T1D was 5/9, islet autoantibody-positive $8 / 14$, and long-standing subjects with T1D 2/4 compared with controls 6/24. To be considered positive, the section stained positive for CAR in a few up to several islets. In CAR-negative sections from either group of donors, no staining of CAR was seen. The positive CAR staining revealed a membranous pattern in the endocrine tissue (figure 1A), suggesting the presence of the transmembraneous part of CAR.

A somewhat less intense cytoplasmic/membranous CAR staining was also observed in cells in the exocrine part of the pancreas in all donors, with CAR-positive endocrine cells. In addition, in five donors with T1D, positive staining for CAR in ductal epithelial cells was seen. In the majority $(30 / 51)$ of the pancreatic sections (mainly controls), no staining for the extracellular domain of CAR was seen in the endocrine or exocrine tissue.

\section{Virus replication}

All EV strains/serotypes used for infection replicated in the islets. The mean virus titer increase in the culture medium during 3 days p.i. was $10^{1.8+0.28}$ (CBV-1-11, $\mathrm{n}=6$ ), $10^{2.5+0.4}(\mathrm{CBV}-1-3, \mathrm{n}=7), 10^{2.5+0.40}(\mathrm{CBV}-1-7, \mathrm{n}=6)$ and $10^{4.5+0.19}$ (echovirus $6-2 \mathrm{C}, \mathrm{n}=5$ ) $\mathrm{TCID}_{50} / 200 \mu \mathrm{L}$, respectively (figure 2).

\section{Expression of CAR mRNA}

In uninfected control islets $(n=3)$, cultured for an extended period postisolation, the expression level of CAR decreased linearly with the time of culture (figure 3). Islets infected in vitro with three strains of CBV-1 revealed a significant $(\mathrm{p}<0.001)$ reduction in CAR coding mRNA compared with uninfected control islets from the same donors $(n=6)$. There were no differences between the CBV-1 strains in that respect. However, in islets infected with echovirus-6-2C, which does not use CAR as a receptor, no reduction of the expression
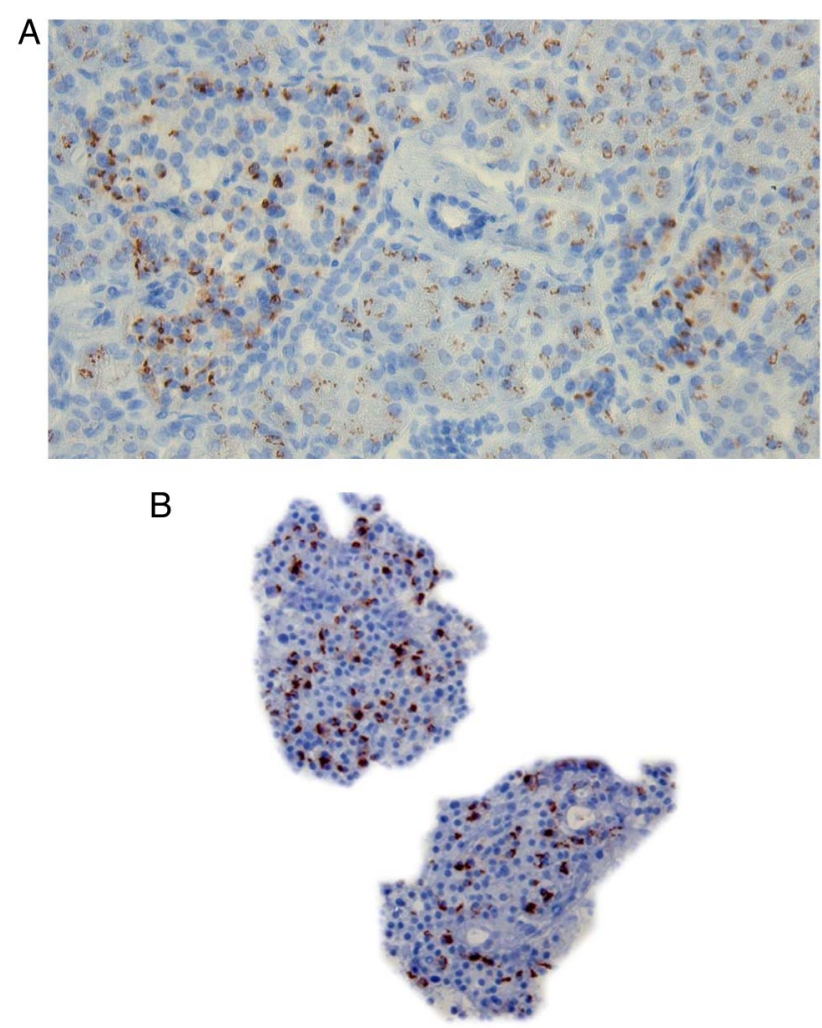

Figure 1 (A) Positive CAR staining in one donor with GAD65 and IA-2 autoantibodies. (B) CAR staining in isolated human islets, from control organ donor, infected with a CBV-1 strain. CAR, coxsackie-adenovirus receptor; CBV, coxsackievirus B.

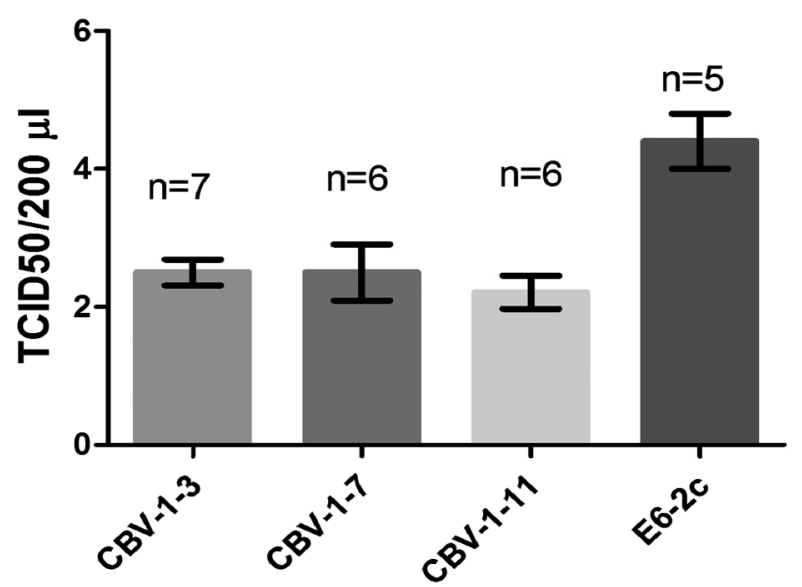

Figure 2 Mean virus titer increase in human islets, from control donors, infected in vitro with CBV-1-3 $(n=7), C B V-1-7$ $(n=6), C B V-1-11(n=6)$ and Echo-6-2C $(n=5)$. CBV, coxsackievirus $\mathrm{B}$.

of CAR mRNA was seen compared with control (figure 4 ), indicating that the effect was not due to virus-induced $\beta$-cell death. Comparing the expression level of CAR between the different CBV-1 strains and the Echo-6-2C revealed that the difference was similar to that of the difference between the control and the CBV-1-infected islets. 


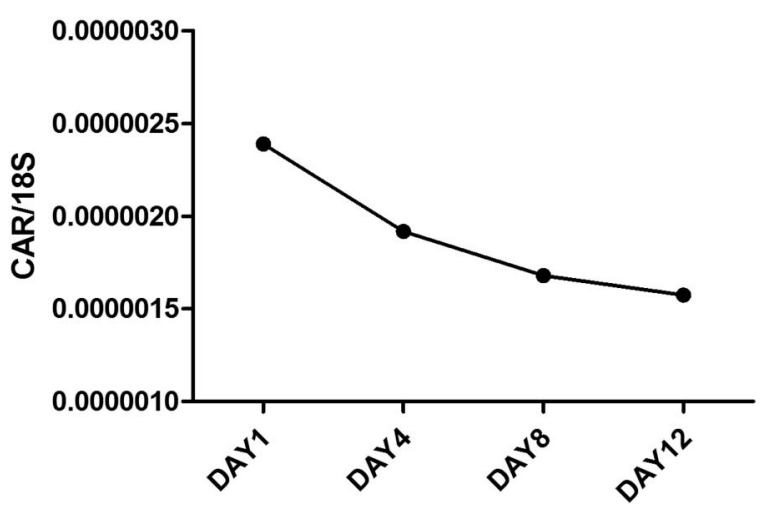

Figure 3 mRNA expression levels of the gene encoding CAR in isolated human islets from control donors, cultured for prolonged time $(n=2)$. Islets were cultured for 1, 4, 8 and 12 days and CAR mRNA expression levels were quantified with qPCR. CAR, coxsackie-adenovirus receptor; qPCR, quantitative PCR.

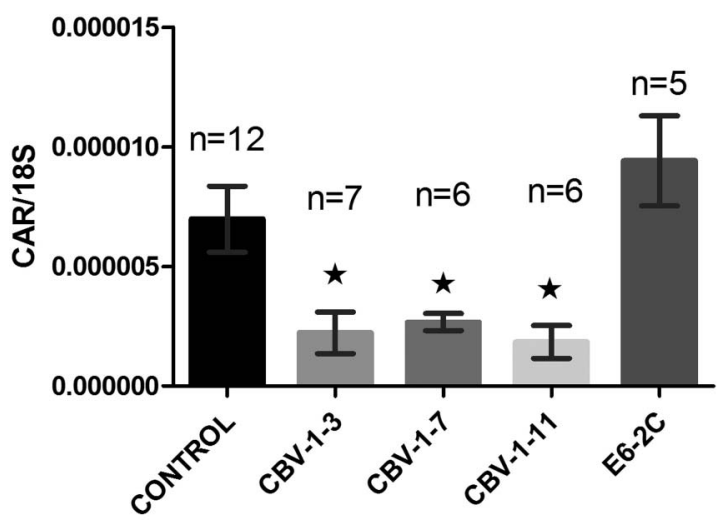

Figure 4 Mean CAR mRNA expression levels in isolated human islets from control donors infected in vitro with different EV strains. CAR expression levels were decreased in all islets infected with strains of CBV-1 compared with the mock-infected control $(p<0.05)$. In islets infected with the non-CAR using E6-2C strain, no affect on the CAR expression level was seen. Bars represent mean \pm SEM. CAR, coxsackieadenovirus receptor; CBV, coxsackievirus B; E6-2C,

Echo-6-2C; EV, enterovirus.

CBV-1-11 and CBV-1-3 differed somewhat more compared with Echo-6-2C $(\mathrm{p}<0.009)$ than CBV-1-7 $(\mathrm{p}<0.004)$. In explanted islets cultured in UV-treated culture medium from infected islets from organ donors, a clear increase of CAR mRNA was seen after 4 days of culture compared with islets cultured in UV-treated islet culture medium from controls (figure 5).

\section{Western blot}

The reduction of the CAR gene seen in islets infected with strains of CBV-1 was also confirmed on the protein level. There was a decreased expression of the CAR protein relative to the housekeeping protein in islets infected with CBV-1-11 compared with that in mockinfected islets from the same donor (figure 6).

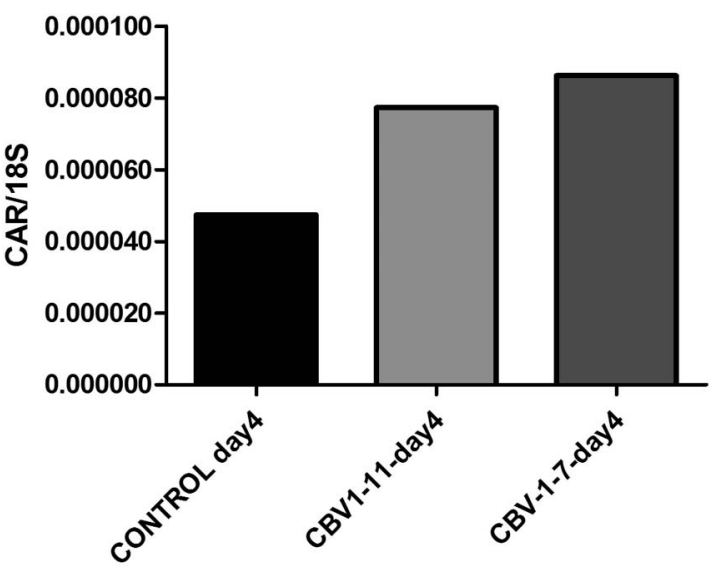

Figure 5 mRNA expression levels of the gene encoding CAR in explanted human islets from control donors, cultured in UV-treated culture medium derived from CBV-infected human islets and from mock infected islets. CAR mRNA expression levels were quantified with qPCR on day 4 of culture. CAR, coxsackie-adenovirus receptor; CBV, coxsackievirus B; qPCR, quantitative PCR; UV, ultraviolet.

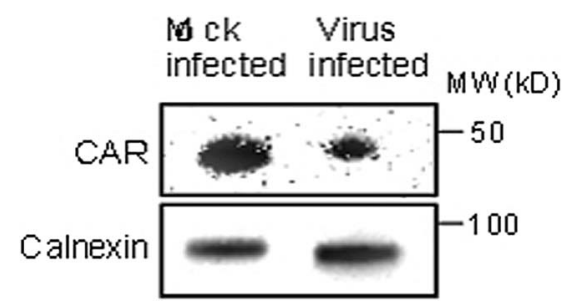

Figure 6 Western blot analysis of explanted human islets from control donors infected in vitro with CBV-1-11 revealed decreased expression of the CAR protein compared with mock-infected islets from the same donor $(n=1)$. CAR, coxsackie-adenovirus receptor; CBV, coxsackievirus B.

\section{DISCUSSION}

In this study, we found that frequency of CAR expression was increased in the pancreatic endocrine tissue from autoantibody-positive non-diabetic donors and subjects with T1D compared with controls. This indicates that CAR may promote virus infection and uptake in endocrine cells of pancreatic islets, previously shown to be permissive to virus infection both in vivo ${ }^{4}$ and in vitro. ${ }^{12}$ The reason for the higher percentage CAR positivity in patients with T1D and prediabetes is not known, but studies have shown that CAR expression can be induced by inflammation and tissue damage. ${ }^{29}$ CAR has been shown to be an inducible protein and increased expression of CAR has been reported in myocytes in dilated cardiomyopathy $^{30}$ and in hearts from subjects with myocardial infarction. ${ }^{24}$ Increased CAR expression has also been associated with an ongoing inflammation ${ }^{29}$ and during formation of cell-to-cell contact due to tissue destruction. $^{24} 25$ In fact, we found that UV-treated culture supernatants of CBV-infected islets induced similar CAR expression on culture islets, suggesting that 
CBV infection in islets of Langerhans could be one possible cause of CAR expression in islets. This supernatant did not contain infectious virus particles, suggesting that the effect was due to some inflammatory mediators induced by the virus in infected islets. Previous studies have shown that CBV infection of human islets induces several cytokines and chemokines. ${ }^{36}{ }^{37}$ We tested the effect of one of the most abundantly produced chemokines, CXCL10, on islets, but it failed to induce CAR. Thus, further studies are needed to identify virus-induced substances that mediate induction of CAR on human islets. In addition to viral factors, other factors, such as the autoimmune process itself, may be involved.

Regardless of the cause of the induction of the splice variant of CAR that is used by CBV for infection, induction of this protein may make islet more susceptible for CBV infection and also promote the spread of ongoing infection to other islets. ${ }^{17}$

The expression of CAR in islets from donors with islet autoantibodies or T1D suggests that islets in these individuals are potentially more susceptible to CBV infection. In humans, in contrast to in mice, it seems that islet of Langerhans are the target tissue for CBV. In contrast to our findings in humans, in situ hybridization in pancreatic tissue from mice has failed to show any expression of CAR mRNA in the islets ${ }^{38}$ that might explain why mouse islets are normally spared during CBV infection. ${ }^{38} 39$

Most studies have failed to detect EV in human exocrine tissue, that is, in neonates with systemic EV infections. ${ }^{4}$ In vitro studies, in which primary human exocrine cells were inoculated with two strains of CBV-5, failed to show any replication and no virus particles could be detected by electron microscopy in the cells. ${ }^{12}$

Staining for the extracellular domain of CAR on pancreatic tissue sections revealed that most non-diabetic donors did not express the extracellular domain of CAR. In contrast, CAR (protein and gene) was expressed in explanted islets from all donors tested. Prolonged culture of isolated islets revealed that the expression of the CAR gene decreased with time of culture, suggesting that the digestive process of the pancreas during islet isolation might cause an induction of CAR.

In vitro infection of islets with EVs revealed that in islets infected with CAR using viruses, the expression of CAR was decreased, in contrast infection with a non-CAR using EV, the expression level of CAR was not affected. One possible explanation for the reduced expression could be a species-specific downregulation of virus receptors, which might lead to inhibition of infection by a second virus, the so-called superinfection exclusion. ${ }^{40}$ This phenomenon has also been described for several other viruses ${ }^{41}$ and might favor a slowgrowing, persistent strain. Whether the downregulation is due to stimulation of certain cytokines, which in vitro have been shown to decrease the expression level of the CAR gene ${ }^{42}$ and also the CAR protein by promotion of turnover of CAR protein through ubiquitin-proteasome and nuclear factor kappa-light-chainenhancer of activated B cells (NFkB)-dependent pathways ${ }^{43}$ or some other factors, remains to be elucidated. A more likely explanation might be that CAR is downregulated by hsa-miR-466d; this has recently been shown in a rodent b-cell model challenged with CBV-4. ${ }^{44}$

In contrast to the decreased expression of CAR during an acute CBV infection in islet endocrine cells, the expression of CAR in individuals with acute EV infection in myocytes was increased..$^{30}$ Also in EV-positive cases with dilated cardiomyopathy, a disease with a chronic EV infection, the expression of the CAR protein was increased compared with controls. ${ }^{45}$ Systemic EV infection has during some epidemics resulted in seroconversion of islet-related autoantibodies, indicating that viral replication has taken place in the islet cells, with release of intracellular proteins as a result. ${ }^{46}$ If such an infection, in a subgroup of infected individuals, progressed to a chronic phase with a low-grade viral replication and ongoing tissue damage, CAR might be induced by $\mathrm{EV}$ infection. This has been shown regarding myocarditis and its progression in some individuals to dilated myopathy. ${ }^{47}$

In summary, this study shows that the CAR protein is expressed in islets of Langerhans in a higher percentage of individuals with T1D or at risk of T1D compared with non-diabetic individuals. Increased expression of CAR is also seen after treatment with proinflammatory cytokines/chemokines, and induction of this protein in pancreatic islets in vivo might induce a fertiled field and this may also promote the spread of CBV to other islet and play a role in virus-induced T1D.

\section{Author affiliations}

${ }^{1}$ Department of Immunology, Genetics and Pathology, Uppsala University, The Rudbeck Laboratory, Uppsala, Uppland, Sweden

${ }^{2}$ Department of Microbiology, Tumor and Cell biology, Karolinska Institutet, Stockholm, Sweden

${ }^{3}$ Division of Paediatric and Adolescent Medicine, Oslo University Hospital, Oslo and Faculty of Medicine, University of Oslo, Oslo, Norway

${ }^{4}$ Department of Virology, University of Tampere, Tampere, Finland

${ }^{5}$ FimlabLaboratories, Pirkanmaa Hospital District, Tampere, Finland

${ }^{6}$ Autoimmunity Unit, Department of Clinical Sciences, Skåne University Hospital, Lund University, Malmo, Sweden

Acknowledgements The authors thank Inga Hansson for her technical assistance with the IHC.

Collaborators POD-V Consortium, http://www.jdrfnpod.org/publications/ npod-viral-work-group/.

Funding This work was supported by funding from the European Union's Seventh Framework Programme PEVNET (FP7/2007-2013) under grant agreement number 261441 and from a Diabetes Research Wellness Foundation Non-clinical Research Fellowship, Barndiabetes fonden, Swedish diabetes association and Network for Pancreatic Organ Donors with Diabetes (nPOD), a collaborative type 1 diabetes research project sponsored by the Juvenile Diabetes Research Foundation International (JDRF). The DiViD study was funded by the Norweigian South East Helth Region, The Novo Nordisk Foundation and PEVNET. Organ Procurement Organizations (OPO) partnering with nPOD to provide research resources are listed at http://www.jdrfnpod.org/ our-partners.php. 
Competing interests None declared.

Ethics approval The ethical committee at Oslo university hospital and the ethical committee at Uppsala University.

Provenance and peer review Not commissioned; externally peer reviewed.

Data sharing statement No additional data are available.

Open Access This is an Open Access article distributed in accordance with the Creative Commons Attribution Non Commercial (CC BY-NC 4.0) license, which permits others to distribute, remix, adapt, build upon this work noncommercially, and license their derivative works on different terms, provided the original work is properly cited and the use is non-commercial. See: http:// creativecommons.org/licenses/by-nc/4.0/

\section{REFERENCES}

1. Kondrashova A, Reunanen A, Romanov A, et al. A six-fold gradient in the incidence of type 1 diabetes at the eastern border of Finland. Ann Med 2005;37:67-72.

2. Redondo MJ, Jeffrey J, Fain PR, et al. Concordance for islet autoimmunity among monozygotic twins. N Engl J Med 2008;359:2849-50

3. Elshebani A, Olsson A, Westman J, et al. Effects on isolated human pancreatic islet cells after infection with strains of enterovirus isolated at clinical presentation of type 1 diabetes. Virus Res 2007:124:193-203

4. Ylipaasto $\mathrm{P}$, Klingel $\mathrm{K}$, Lindberg $\mathrm{AM}$, et al. Enterovirus infection in human pancreatic islet cells, islet tropism in vivo and receptor involvement in cultured islet beta cells. Diabetologia 2004:47:225-39.

5. Richardson SJ, Leete $\mathrm{P}$, Bone AJ, et al. Expression of the enteroviral capsid protein VP1 in the islet cells of patients with type 1 diabetes is associated with induction of protein kinase $\mathrm{R}$ and downregulation of Mcl-1. Diabetologia 2013;56:185-93.

6. Oikarinen S, Martiskainen M, Tauriainen S, et al. Enterovirus RNA in blood is linked to the development of type 1 diabetes. Diabetes 2011;60:276-9.

7. Yoon JW, Austin M, Onodera T, et al. Isolation of a virus from the pancreas of a child with diabetic ketoacidosis. $N$ Engl J Med 1979;300:1173-9.

8. Yin $\mathrm{H}$, Berg AK, Tuvemo $\mathrm{T}$, et al. Enterovirus RNA is found in peripheral blood mononuclear cells in a majority of type 1 diabetic children at onset. Diabetes 2002;51:1964-71.

9. Frisk G, Fohlman J, Kobbah M, et al. High frequency of coxsackie-B-virus-specific IgM in children developing type I diabetes during a period of high diabetes morbidity. J Med Virol 1985;17: 219-27.

10. Krogvold L, Edwin B, Buanes T, et al. Detection of a low-grade enteroviral infection in the islets of Langerhans of living patients newly diagnosed with type 1 diabetes. Diabetes 2015:64:1682-7.

11. Frisk G, Diderholm H. Tissue culture of isolated human pancreatic islets infected with different strains of coxsackievirus B4: assessment of virus replication and effects on islet morphology and insulin release. Int J Exp Diabetes Res 2000;1:165-75.

12. Hodik M, Lukinius A, Korsgren O, et al. Tropism analysis of two coxsackie B Strains reveals virus growth in human primary pancreatic islets but not in exocrine cell clusters in vitro. Open Virol $J$ 2013;7:49-56.

13. Anagandula M, Richardson $\mathrm{S}$, Skog $\mathrm{O}$, et al. Infection of human islets of Langerhans with two strains of coxsackie B virus serotype 1 ; assessment of virus replication, degree of cell death and induction of genes involved in the innate immunity pathway. J Med Virol 2014;86:1402-11.

14. Frisk $\mathrm{G}$, Elfstrom $\mathrm{T}$, Diderholm $\mathrm{H}$. The replication of certain coxsackie B virus strains in CHO cells. $J$ Virol Methods 2001;98: $161-5$.

15. Shafren DR, Bates RC, Agrez MV, et al. Coxsackie viruses B1, B3, and B5 use decay accelerating factor as a receptor for cell attachment. J Virol 1995;69:3873-7.

16. Bergelson JM, Cunningham JA, Droguett G, et al. Isolation of a common receptor for coxsackie B viruses and adenoviruses 2 and 5. Science 1997:275:1320-3.

17. Bergelson JM, Krithivas A, Celi L, et al. The murine CAR homolog is a receptor for coxsackie $B$ viruses and adenoviruses. $J$ Virol 1998;72:415-19.

18. Excoffon KJ, Gansemer ND, Mobily ME, et al. Isoform-specific regulation and localization of the coxsackie and adenovirus receptor in human airway epithelia. PLOS ONE 2010;5:e9909.
19. Thoelen I, Magnusson C, Tagerud S, et al. Identification of alternative splice products encoded by the human coxsackie-adenovirus receptor gene. Biochem Biophys Res Commun 2001:287:216-22.

20. Dorner A, Xiong D, Couch $\mathrm{K}$, et al. Alternatively spliced soluble coxsackie-adenovirus receptors inhibit coxsackievirus infection. J Biol Chem 2004;279:18497-503.

21. He Y, Chipman PR, Howitt J, et al. Interaction of coxsackievirus B3 with the full length coxsackievirus-adenovirus receptor. Nat Struct Biol 2001;8:874-8.

22. Wang X, Bergelson JM. Coxsackievirus and adenovirus receptor cytoplasmic and transmembrane domains are not essential for coxsackievirus and adenovirus infection. $J$ Virol 1999;73:2559-62.

23. Tomko RP, Xu R, Philipson L. HCAR and MCAR: the human and mouse cellular receptors for subgroup $C$ adenoviruses and group $B$ coxsackieviruses. Proc Natl Acad Sci USA 1997;94:3352-6.

24. Fechner $\mathrm{H}$, Noutsias $\mathrm{M}$, Tschoepe $\mathrm{C}$, et al. Induction of coxsackievirus-adenovirus-receptor expression during myocardial tissue formation and remodeling: identification of a cell-to-cell contactdependent regulatory mechanism. Circulation 2003;107:876-82.

25. Honda T, Saitoh H, Masuko M, et al. The coxsackievirus-adenovirus receptor protein as a cell adhesion molecule in the developing mouse brain. Brain Res Mol Brain Res 2000;77:19-28.

26. Raschperger E, Thyberg J, Pettersson S, et al. The coxsackie- and adenovirus receptor (CAR) is an in vivo marker for epithelial tight junctions, with a potential role in regulating permeability and tissue homeostasis. Exp Cell Res 2006;312:1566-80.

27. Drescher KM, Kono K, Bopegamage S, et al. Coxsackievirus B3 infection and type 1 diabetes development in NOD mice: insulitis determines susceptibility of pancreatic islets to virus infection. Virology 2004;329:381-94.

28. Hsu KH, Lonberg-Holm K, Alstein B, et al. A monoclonal antibody specific for the cellular receptor for the group B coxsackieviruses. $J$ Virol 1988;62:1647-52.

29. Ito M, Kodama M, Masuko M, et al. Expression of coxsackievirus and adenovirus receptor in hearts of rats with experimental autoimmune myocarditis. Circ Res 2000;86:275-80.

30. Noutsias $\mathrm{M}$, Fechner $\mathrm{H}$, de Jonge $\mathrm{H}$, et al. Human coxsackie-adenovirus receptor is colocalized with integrins alpha(v) beta(3) and alpha(v)beta(5) on the cardiomyocyte sarcolemma and upregulated in dilated cardiomyopathy: implications for cardiotropic viral infections. Circulation 2001;104:275-80.

31. Kuster K, Koschel A, Rohwer N, et al. Downregulation of the coxsackie and adenovirus receptor in cancer cells by hypoxia depends on HIF-1alpha. Cancer Gene Ther 2010;17: 141-6.

32. Goto M, Eich TM, Felldin M, et al. Refinement of the automated method for human islet isolation and presentation of a closed system for in vitro islet culture. Transplantation 2004;78:1367-75

33. Bergelson JM, Chan M, Solomon KR, et al. Decay-accelerating factor (CD55), a glycosylphosphatidylinositol-anchored complement regulatory protein, is a receptor for several echoviruses. Proc Natl Acad Sci USA 1994;91:6245-8.

34. Moell A, Skog O, Ahlin E, et al. Antiviral effect of nicotinamide on enterovirus-infected human islets in vitro: effect on virus replication and chemokine secretion. J Med Virol 2009;81:1082-7.

35. Nyström N, Berg T, Lundin E, et al. Human enterovirus species B in ileocecal Chron's disease. Clin Trans/ Gastroenterol 2013 Jun 27; 4:e38.

36. Olsson $\mathrm{A}$, Johansson $\mathrm{U}$, Korsgren $\mathrm{O}$, et al. Inflammatory gene expression in coxsackievirus B-4-infected human islets of Langerhans. Biochem Biophys Res Commun 2005;330:571-6.

37. Anagandula M, Richardson SJ, Oberste MS, et al. Infection of human islets of Langerhans with two strains of coxsackie $B$ virus serotype 1: assessment of virus replication, degree of cell death and induction of genes involved in the innate immunity pathway. J Med Virol 2014;86:1402-11.

38. Mena I, Fischer C, Gebhard JR, et al. Coxsackievirus infection of the pancreas: evaluation of receptor expression, pathogenesis, and immunopathology. Virology 2000;271:276-88.

39. Bopegamage S, Kovacova J, Vargova A, et al. Coxsackie B virus infection of mice: inoculation by the oral route protects the pancreas from damage, but not from infection. J Gen Virol 2005;86(Pt 12):3271-80.

40. Tscherne DM, Evans MJ, von Hahn T, et al. Superinfection exclusion in cells infected with hepatitis $C$ virus. J Virol 2007;81:3693-703.

41. Simon KO, Cardamone JJ Jr, Whitaker-Dowling PA, et al. Cellular mechanisms in the superinfection exclusion of vesicular stomatitis virus. Virology 1990;177:375-9. 
42. Vincent T, Pettersson RF, Crystal RG, et al. Cytokine-mediated downregulation of coxsackievirus-adenovirus receptor in endothelial cells. J Virol 2004;78:8047-58.

43. Gao Y, Lui WY. Synergistic effect of interferon-gamma and tumor necrosis factor-alpha on coxsackievirus and adenovirus receptor expression: an explanation of cell sloughing during testicular inflammation in mice. Biol Reprod 2014;90:59.

44. Lam WY, Cheung AC, Tung CK, et al. miR-466 is putative negative regulator of coxsackie virus and adenovirus receptor. FEBS Lett 2015;589:246-54.
45. Liu Q, Su XJ, Yu Y, et al. Correlations among persistent viral infection, heart function and Chinese medicine syndromes in dilated cardiomyopathy patients. Chin J Integr Med 2014;20:928-33.

46. Sarmiento L, Cubas-Duenas I, Cabrera-Rode E. Evidence of association between type 1 diabetes and exposure to enterovirus in Cuban children and adolescents. MEDICC Rev 2013;15:29-32.

47. Chapman NM, Kim KS, Drescher KM, et al. 5 terminal deletions in the genome of a coxsackievirus B2 strain occurred naturally in human heart. Virology 2008;375:480-91. 